\title{
A methodology for improving road safety by novel infrastructural and invehicle technology combinations
}

\author{
Marion Wiethoff • Karel Brookhuis • Dick de Waard • \\ Vincent Marchau • Leonie Walta • Guenter Wenzel • \\ Klaas de Brucker $\cdot$ Cathy Macharis
}

Received: 29 September 2008 / Accepted: 14 November 2011 / Published online: 2 February 2012

(C) The Author(s) 2012. This article is published with open access at SpringerLink.com

\begin{abstract}
Introduction Still too many deaths and injuries are a result of road safety limitations within Europe. Road safety measures aimed to change the road environment to reduce the risks on driver errors and to reduce the seriousness of the effects of driver errors are expected to increase road safety. A suitable combination of new technologies with existing infrastructure, or with limited improvements of it, may lead to much more cost-effective solutions (Brookhuis et al. 2006). The In-Safety project was aimed at determining which safety measures are expected to be most effective and in the project also evaluations were performed in pilot sites and modeling laboratories. Methods The methodological approach for the selection and prioritization of the initial set of safety measures is
\end{abstract}

M. Wiethoff $(\bowtie) \cdot$ K. Brookhuis $\cdot$ V. Marchau $\cdot$ L. Walta

Department of Transport Policy \& Logistics,

Delft University of Technology,

Jaffalaan 5,

NL-2628 BX, Delft, the Netherlands

e-mail: marionwiethoff@gmail.com

D. de Waard

Faculty of Behavioural and Social Sciences,

University of Groningen,

Groningen, The Netherlands

G. Wenzel

Institute for Human Factors and Technology Management (IAT),

University of Stuttgart,

Stuttgart, Germany

K. de Brucker

University College Brussels,

Brussels, Belgium

C. Macharis

Vrije Universiteit Brussel, Vakgroep MOSI-Transport \& Logistics, Brussels, Belgium presented and discussed, based on an accident analysis. First, the general approach is described, then the method is presented including the definition of a scenario, how accident statistics are used as a starting point, the generation of safety measures, and the method of selection of safety measures. Finally, the AHP multicriteria analysis method, involved in the final prioritisation of the selected safety measures is presented briefly.

Results and conclusion The methodology proves to be appropriate for generating and evaluating self explaining road environment measures and forgiving measures, but safety measures in the urban environment were underrepresented, due to stakeholders' preferences.

Keywords Road safety $\cdot$ Safety measures $\cdot$ Methodological approach $\cdot$ ADAS $\cdot$ Forgiving road $\cdot$ Self explaining road

\section{Introduction}

The EU project IN-SAFETY, (FP6, 506716; 2005-2008) was aimed to identify and evaluate intelligent, intuitive and cost-efficient combinations of new technologies and traditional infrastructure best practice applications. This was intended to enhance the forgiving and selfexplanatory character of roads. The project involved, amongst others, assessing the potential and cost-effectiveness of combined use of new technologies and innovative HMI concepts, developing new simulation models, risk analysis tools, harmonising signing and personalising information, and issuing priority implementation scenarios.

In the project, we investigated what possibilities there are for new combinations in infrastructure and in-vehicle systems in order to raise road safety. The reason for this, is that the costs in terms of human suffering and economic loss as a 
result of road accidents are still considerable. Furthermore, a major cause of accidents are human errors. Studies on effectiveness of casualty reduction measures in Greece demonstrated that the largest reduction is to be expected from vehicle crash protection (15\%), measures to prevent from driving-while-intoxicated are second with $11 \%$, while road safety engineering measures are expected to result in a reduction of $6.5 \%$. These figures are more or less representative for Europe. Next to their relatively limited effectiveness, road safety measures result in high costs. Therefore, due to the high cost of such measures, infrastructure improvements are not expected to be implemented widely and hence contribute marginally to a major reduction of road fatalities. However, a suitable combination of new technologies with existing infrastructure, or with limited improvements of it, may lead to much more cost-effective solutions [1]. As such, these innovative solutions may become the catalyst towards achieving the EU goal of halving the number of road accidents in 2010 as compared to 2000.

Therefore, it is to be expected that an environment that is self-explaining and of a forgiving nature will enhance safety, and that this type of environment particularly combines infrastructure and in-vehicle measures. The In-Safety project was designed to study the opportunities for improving the road environment in these respects to increase road safety. The basic assumption of In-Safety was that the combination of infrastructure and telematics measures can provide a more cost-efficient solution, avoiding performing expensive infrastructure works by providing the same function through a telematics or other innovative system. InSafety focused especially on the cooperative systems: in car-vehicle systems combined with infrastructural systems

A self-explaining road (SER) is designed and constructed to evoke correct expectations from road users, eliciting proper driving behaviour, in this way reducing the chance on driver errors and enhancing driving comfort. A forgiving road (FOR) is defined as a road that is designed and built in such a way as to interfere with or block the development of driving errors and to avoid or mitigate negative consequences of driving errors.

In the current paper, the methodology is presented which is developed and applied for defining the priority scenarios for devising self explaining road environments and forgiving road environments aimed at improving road safety. First, the general approach is described, then the method is presented including the definition of a scenario, how accident statistics are used as a starting point, the generation of safety measures, and the method of selection of safety measures. The safety analysis for each of the measures will be reported elsewhere (Wiethoff et al, in prep.). Finally, the AHP multicriteria analysis method, involved in the final prioritisation of the selected safety measures is presented only briefly. This method and the application of the method on these data is described in detail in De Brucker et al (2007).

\section{Research approach}

To identify and evaluate the possible measures that can constitute a working self-explaining road and/or an effective forgiving road environment, the following approach had been chosen (Fig. 1).

1. First we needed to establish how to define and to select the type of driver errors for which FOR and SER solutions could work. After long discussions, it was decided to start from the observable facts (the accidents in the available accident statistics) and then to select the type of accidents most severe or most frequent, and then find a valid framework to select the relevant driver errors. The analysis of accident statistics was performed. German accident statistics were selected, for their quality, the availability of details on the causes, and being representative for the EU as a whole [4]. These were then translated in terms of 5 types of driver errors, e.g. speeding, wrong use of the lane, etc. The project consortium added one more driver error: "driving too fast near an unexpected bend on rural roads". Reason's framework of errors was chosen in order to define levels of driver errors.

2. Second, to be able to select the best FOR and SER solutions for each driver error, a large set of possible solutions was generated to choose from. An extensive number of safety measures to mitigate these driver errors were generated for three different road types: urban roads, rural roads and motorways. The safety measures were associated specifically to the driver errors and the road types. For each error type a typical solution was defined, but in 3 technological varieties: infrastructural measures, in-vehicle measures and combined measures.

3. Third, these safety measures were evaluated on their potential safety effects, based on literature reviews.

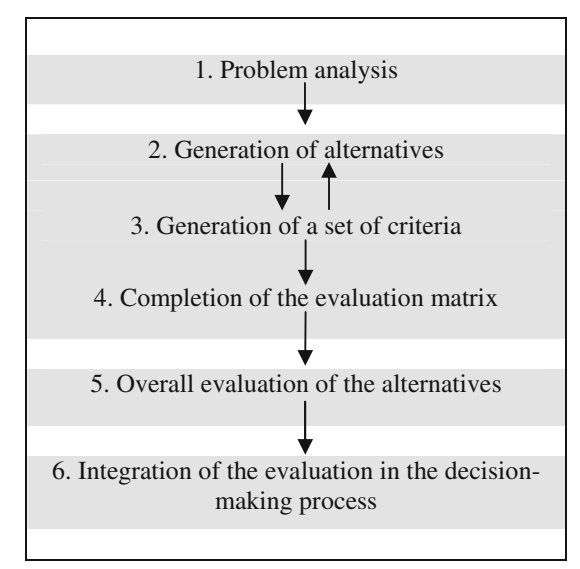

Fig. 1 Overview of the procedure in IN-SAFETY project for selecting new measures to improve road safety 
4. Fourth, it was decided that the project would deal with a limited set of solutions (as was the scope of the project). A set of 18 most promising safety measures was selected from the initial set, representing the self-explaining or forgiving character of a road. The set of 18 alternatives resulted from safety measures on 6 types of driver errors, in 3 different technological varieties: in-vehicle, infrastructure and combined technologies. Detailed scenarios were designed, in order to be able to study more specifically the expected safety effects,

5. Next, the potential of these measures to contribute to road safety was further estimated, applying advanced micro- and macro safety modelling, or literature analysis of previous empirical data on experiments and pilot studies. The estimation was performed for different road types, driver types, vehicle types. However, there were also a number of other (decisive) criteria. For this study, three categories of stakeholders were identified: drivers, the society as a whole (public authorities), and manufacturers. For each stakeholder, different criteria would be prevalent. Some examples are: for drivers: user costs, user comfort, for public authorities: overall safety, for manufacturers: investment risk. Stakeholders' opinion is crucial for any of the above measures to be effective. They may foresee difficulties in implementation. Each stakeholder performs an evaluation of the safety measure in terms of his own objectives.

6. Since it is unlikely that all criteria are equally important to the stakeholders, the stakeholders are assumed to weigh each criterion. These weights were measured, and together with the different measures and the criteria developed by them, these are used as inputs to their own Multi Criteria Analysis (MCA). The relative weights to above criteria were generated to get an idea about which measures are most likely to be successfully implemented. This was done by questioning stakeholderrepresentatives in a multi-criteria analysis session, using the analytic hierarchy process (AHP) method of Saaty [8], and applied earlier [3]. This part of the study is reported elsewhere (de Brucker et al, in preparation).

7. Based upon these results a set of most promising measures for implementation could be considered, and the path to implementation for each of these promising measures should be developed. This involved an analysis of stakeholder opinions regarding different promising measures in terms of stakeholder preferences and the in case of (conflicting) differences in preferences among stakeholders, i.e. obstructing implementation, looking for way's to bridge these differences.

This approach will be shown and illustrated in the current paper. Therefore, not all the details of each step will be shown in great detail.

\section{Method}

\subsection{Definition of a scenario}

A scenario is a key methodology element in defining the prevailing conditions outside (and inside) the vehicle which strongly influence the outcomes of a safety measure. Scenario specification and assessment parameter definitions for outcome effects have to be included when assessment of safety measures are developed.

Here, a scenario is defined as a conglomerate of 5 types of elements (conditions), defining the conditions of the driver-vehicle system on the road in which an ADAS (Advanced Driver Assistance System) is implemented ([11]: ADVISORS project). The five conditions are shown in Table 1, first column.

One way of illustrating the scenario concept is shown in Fig. 2. The components are related to each other and interact in different ways in different cases. The ADAS implementation may have very different effects (e.g. safety effects, effects on speed, network efficiency, environmental load) for different scenarios. In the approach for assessment of safety measures to promote forgiving road and selfexplaining road environments scenarios are applied to define the specific circumstances and evaluate safety measures accordingly.

The conditions of the five above mentioned types of elements should be filled in explicitly in order to identify and assess the effects of a specific road safety measure.

In this study, the parameters selected are presented in Table 1, second column.

\subsection{Accident statistics}

Devising the measures for forgiving road environments, as they by definition aim at avoiding or mitigating negative consequences of driving errors, starts with listing possible driving errors to be supported that in turn are related to accident statistics. The latter is important since predictions about safety effects can only be based on supporting

Table 1 Conditions, constituting a scenario and for each condition the parameters chosen in the current study

\begin{tabular}{|c|c|}
\hline Conditions & Parameters \\
\hline 1. the driver & age, gender, driver type, driving experience \\
\hline 2. the vehicle & type (light vehicle- heavy vehicle), status \\
\hline 3. the road infrastructure & road type (urban, rural, motorway) \\
\hline 4. the traffic conditions & density, speed \\
\hline $\begin{array}{l}\text { 5. the environmental } \\
\text { conditions }\end{array}$ & weather, road surface, lighting \\
\hline
\end{tabular}




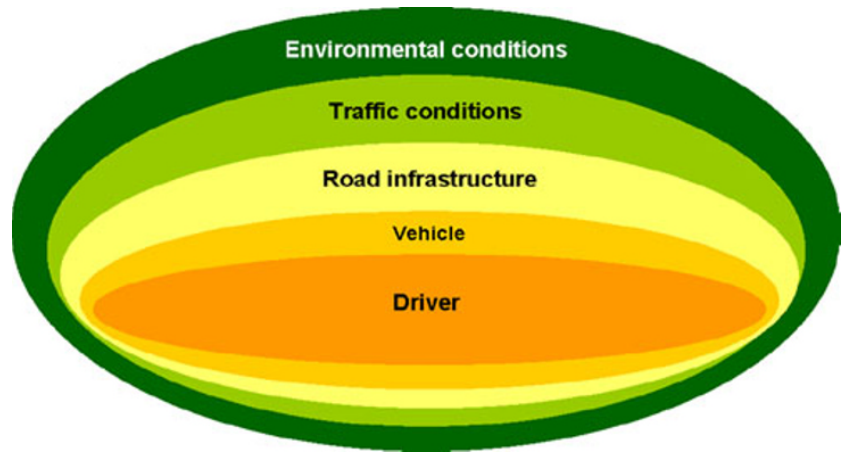

Fig. 2 Defining scenarios in terms of relevant conditions

(avoiding, mitigating) safetyrelated errors. Lotz et al. [5] have made a categorisation of errors based on stages in the cause-effect chain (Table 2).

Table 2 shows, following the CARE database [9], the Level 1 errors to be distinguished are listed in decreasing fatalities in Germany. Level 2 errors can be distinguished by following the accident causes that are defined in the German accident databases. There are very many different examples of accident causes in Germany, the top 6 are listed in Table 2.

For the Level 3 errors, the information processing error types: information error, diagnostic error and performance error stem from Rasmussen and Vollrath. Level 4 errors can be distinguished by different causes for reduced psycho-physiological condition. For the generation of alternatives, level 2 errors were taken as a starting point. It was decided to take accident statistics as a starting point. German accident statistics were selected, for their quality and being representative for the $\mathrm{EU}$ as a whole [4,5].

\subsection{Safety measures generation}

For the generation of alternatives, the following types of technological solution can be distinguished. These solutions are based on the type of cooperation, or absence of cooperation between infrastructure and systems.

- Co-operative solutions

- Infrastructure to Vehicle (signals from the infrastructure are sent to the vehicle: e.g. curvature of the bend)

- Vehicle to Vehicle; (signals from one vehicle to one or more other vehicles)

- Infrastructure to Vehicle and Vehicle to Vehicle (combination of the former two solutions)

- Vehicle to Infrastructure (signals from vehicle to infrastructure)

- Autonomous solutions

- Only Infrastructure

- Only Vehicle

- Only road design

Table 2 Categorisation of errors, level 1-3 in accordance to Hacker (2005), distinction within level 3 according to Rasmussen [7] and Vollrath [10]

\begin{tabular}{|c|c|c|}
\hline Error Level & Description & Errors \\
\hline Level 1: "accident type" & Result of the execution of an error & $\begin{array}{l}\text { - Single vehicle accident (with or without collision with an obstacle) } \\
\text { - Frontal collision } \\
\text {-Lateral collision } \\
\text {-Chain/rear collision } \\
\text {-Collision with parked vehicle } \\
\text { - Collision with animal }\end{array}$ \\
\hline Level 2: "driving error" & Action that has led to the accident. & $\begin{array}{l}\cdot \text { Driving too fast in an unexpected bend on rural roads (error 1) } \\
\text {-Speeding (error 2) } \\
\text {-Wrong use of the lane (error 3) } \\
\text {-Violation of priority rules (error } 4 \text { ) } \\
\text { - Failure when overtaking (error } 5 \text { ) } \\
\text {-Insufficient safety distance (error } 6 \text { ) }\end{array}$ \\
\hline Level 3: "human error" & $\begin{array}{l}\text { Psychological process that is basis } \\
\text { to the driving error. }\end{array}$ & $\begin{array}{l}\text {-information error (lack of perception: e.g. having not noticed the traffic sign } \\
\text { while passing) } \\
\text {-diagnostic error (incorrect evaluation of available information) } \\
\text {-performance error (incorrect execution: e.g. having not found the brake pedal) }\end{array}$ \\
\hline $\begin{array}{l}\text { Level 4: "psycho- } \\
\text { physiological condition" }\end{array}$ & $\begin{array}{l}\text { Condition that can influence the } \\
\text { psychological process. }\end{array}$ & $\begin{array}{l}\cdot \text {-impairment } \\
\text { •exhaustion, fatigue } \\
\text { •disorders (neurological, cardiovascular) } \\
\text { •intoxication (alcohol, drugs) }\end{array}$ \\
\hline
\end{tabular}


As mentioned in the Introduction, the basic assumption of In-Safety is that the combination of infrastructure and telematics measures can provide a more cost-efficient solution as compared to a stand alone solution, therefore we devised a way to focus especially on solutions based on cooperative systems. For the generation of alternatives, a matrix (see Fig. 3) was produced.

ADAS were put in one dimension of a matrix (Table 4) on the other dimension the infrastructural measures (Table 3) were listed. The focus is on the crossing points, on the cooperative systems.

The following categories of Infrastructure based measures were distinguished for each error type:

- Road design

- Traffic management

For these Infrastructure based measures, we constituted a list of existing safety measures, and linked these to road safety functions. Please refer to Table 3 .
For the ADAS functionalities, we constituted a similar list of safety functions (Table 4). The following categories of ADAS functionalities were distinguished:

- Longitudinal support

- Collision warning and avoidance

- Lateral support

- Navigation based

- Perception enhancement

- Driver vehicle status monitoring

- Other

A number of measures (solutions) were generated, associated with the six errors. As an example, the measures focussed on "Driving too fast when approaching an unexpected bend on rural road" are shown in Table 5, and "wrong use of lane" are shown in Table 6. Several possible alternative solutions were generated for which these particular errors would cover for the safety hazard: Run-off road or head-on accidents due to inappropriate speed in

\begin{tabular}{|c|c|c|c|c|c|c|c|}
\hline & & $\begin{array}{r}\text { Co- } \\
\text { oporativo } \\
\text { V<>1 }\end{array}$ & $\begin{array}{r}\text { Autonomo } \\
\text { us in- } \\
\text { vehicle }\end{array}$ & $\begin{array}{r}\text { Autonomo } \\
\text { us in- } \\
\text { vehicle }\end{array}$ & $\begin{array}{r}\text { Co. } \\
\text { oporativo } \\
V<\rightarrow 1\end{array}$ & $\begin{array}{l}\text { Autonom } \\
\text { ous in- } \\
\text { vehicle }\end{array}$ & $\begin{array}{l}\text { Autonomou } \\
\text { s in-vehicle }\end{array}$ \\
\hline Infra-structure & ADAS & $\begin{array}{c}\text { Speed Alert } \\
\text { or ISA } \\
\text { based on } \\
\text { digital map } \\
\text { data }\end{array}$ & $\begin{array}{c}\text { Lane } \\
\text { departure } \\
\text { warning }\end{array}$ & $\begin{array}{c}\text { Lane } \\
\text { Keeping } \\
\text { assistant }\end{array}$ & $\begin{array}{l}\text { Navigatio } \\
\text { n system }\end{array}$ & $\begin{array}{c}\text { Vision } \\
\text { enhance } \\
\text { ment }\end{array}$ & $\begin{array}{c}\text { In-Vehicle } \\
\text { HMI } \\
\text { (Displays, } \\
\ldots \text {..) }\end{array}$ \\
\hline Obstacle Free Zone & & & $\mathrm{J}$ & & & & \\
\hline Median Barrier & & & $\mathrm{J}$ & $\mathrm{J}$ & & & \\
\hline Safoty Barrior & & & & & & & \\
\hline Dynamic hazard warning (NMS) & & & G & & & & \\
\hline Protecting Shoulder & & & $J$ & $\mathrm{~J}$ & & & \\
\hline VMS & & & & & & & C \\
\hline $\begin{array}{l}\text { Section speed management system (line or } \\
\text { stretch control) }\end{array}$ & & $E$ & & & & & \\
\hline Lane width & & & $\mathrm{J}$ & J & & & \\
\hline Rumble Strips & & & $\mathrm{J}$ & $\mathrm{J}$ & & & \\
\hline Reflocting road markings & & & $J$ & A J & & A & B \\
\hline Special street lights & & & $J$ & $J$ & & & \\
\hline Road Construction & & & JF & $J F$ & & & \\
\hline Tunnel & & & $\mathrm{J}$ & $\mathrm{J}$ & & & \\
\hline sharp bends & & & $\mathrm{J}$ & A & C & A & AEBD \\
\hline
\end{tabular}

Fig. 3 Selected scenarios arranged to the safety measures. Note that only a selection of the rows and columns are printed to improve readability. The characters in the cells of the table correspond with the characters in the second columns of Tables 5 and 6 . Green: error 1 solutions, red: error 3 solutions 
Table 3 Infrastructure based measures that address road safety functions

\begin{tabular}{|c|c|c|}
\hline Road Safety Functions & Infrastructure Type & Road Safety Measures \\
\hline \multirow[t]{5}{*}{ Collision warning and avoidance } & Road & Obstacle Free Zone \\
\hline & Road & Median Barrier \\
\hline & Road & Safety Barrier \\
\hline & Traffic Management & Dynamic hazard warning (VMS) \\
\hline & Traffic Management & Dynamic Speed-(VMS) \\
\hline \multirow[t]{5}{*}{ Longitudinal Support } & Road & Protecting Shoulder \\
\hline & Road & static traffic signs \\
\hline & Road & traffic lights \\
\hline & Road & VMS \\
\hline & Traffic Management & Section speed management system (line or stretch control) \\
\hline \multirow[t]{2}{*}{ Lateral Support } & Road & Lane width \\
\hline & Road & Rumble Strips \\
\hline \multirow[t]{3}{*}{ Navigation based } & Road & Route signing \\
\hline & Traffic Management & Dynamic Route guidance system (VMS) RDS-TMS Radio-Data-System Traffic \\
\hline & Traffic Management & Message Channel \\
\hline \multirow[t]{4}{*}{ Perception Enhancement } & Traffic Management & Fog warning system (VMS) \\
\hline & Traffic Management & Low friction warning system (VMS) \\
\hline & Road & Reflecting road markings \\
\hline & Road & Special street light \\
\hline Driver-/Vehicle Status Monitoring & & \\
\hline
\end{tabular}

unexpected bends, and for the safety hazard: Accidents due to lane departure. Then, these alternative solutions were dedicated to particular scenarios for which the alternative would be most suitable. The technology and communication type is listed, and, based on literature reviews: the expected safety level of these solutions estimated.

Table 4 ADAS based measures that address road safety functions

\begin{tabular}{|c|c|c|}
\hline Road Safety Functions & ADAS Type & Road Safety Measures \\
\hline \multirow[t]{4}{*}{ Collision warning and avoidance } & Autonomous in-vehicle & Near field collision warning or Side Obstacle detection \\
\hline & Autonomous in-vehicle & Obstacle \& Collision Avoidance \\
\hline & Autonomous in-vehicle Co-operative & Obstacle \& collision warning \\
\hline & Vehicle Vehicle / Vehicle Infra and Infra Vehicle & Local hazard warning \\
\hline \multirow[t]{4}{*}{ Longitudinal Support } & Autonomous in-vehicle Co-operative & Speed Alert or ISA based on traffic sign recognition \\
\hline & Vehicle Infra and Infra Vehicle & Speed Alert or ISA based on digital map data \\
\hline & Autonomous in-vehicle & ACC-Stop \& Go \\
\hline & Co-operative V V & ACC-Stop \& Go + Foresight \\
\hline \multirow[t]{4}{*}{ Lateral Support } & Autonomous in-vehicle & Blind Spot detection \\
\hline & Autonomous in-vehicle & Lane change assistant \\
\hline & Autonomous in-vehicle & Lane departure warning \\
\hline & Autonomous in-vehicle Co-operative & Lane keeping assistant \\
\hline Navigation based & Vehicle Infra and Infra Vehicle & Navigation system \\
\hline \multirow[t]{2}{*}{ Perception Enhancement } & Autonomous in-vehicle & Low friction warning system (in-vehicle) \\
\hline & Autonomous in-vehicle & Vision enhancement \\
\hline \multirow[t]{2}{*}{ Driver-/Vehicle Status Monitoring } & Autonomous in-vehicle & Driver Monitoring \\
\hline & Autonomous in-vehicle & Vehicle Monitoring \\
\hline Several & Autonomous in-vehicle & In-Vehicle HMI (Displays, ...) \\
\hline
\end{tabular}




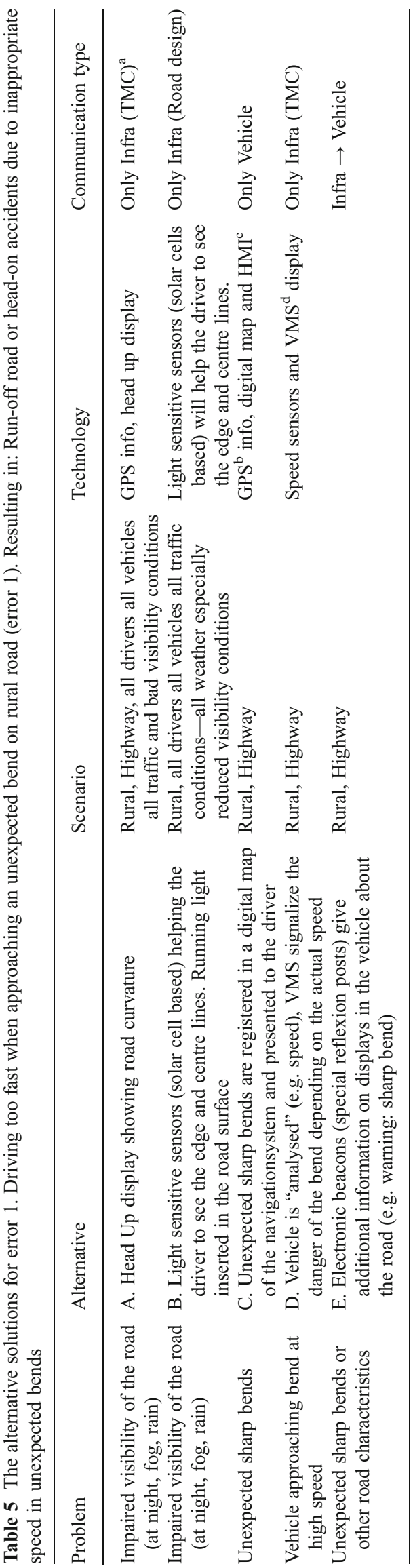

\subsection{Evaluation of safety effects}

As a method to evaluate the co-operative characteristics of the measures developed within the project a matrix has been build that settles the scenarios between the dimensions "in-car vehicle systems" and "road side measures". Figure 3 shows this matrix with the selected scenarios described more detailed in Table 5 , in order to show a more clear vision of the alternatives. In the matrix, in-vehicle systems were put in one dimension of the matrix (green colour), on the other dimension the infrastructural measures (orange colour) were listed.

In the rows all types of ADAS functionalities are listed that are involved in the project: Collision warning and avoidance types, Longitudinal support, Lateral support, Navigation based systems, Perception enhancement, Driver vehicle status monitoring, others, and in the Autonomous variety and the cooperative in-vehicle-infrastructure variety. In the columns, the corresponding infrastructural (mainly classic), measures are listed. Some examples are: obstacle free zone, rumble strips, reflecting road markings, protective shoulder.

The main intention of this method was to give an overview of the scenario distribution to the safety measures. Since one scenario can supplement more than one safety measure either on the in-vehicle or the infrastructural side, multiple mentions of one scenario can be found. The main focus is here on the crossing points, on the co-operative systems.

Even if the focus is on co-operative systems, autonomous system measures have been kept to provide a comparison between all measures during the further process. To reduce the amount of measures for further evaluation the measures have been consolidated.

The detailed results of the safety analysis will be reported elsewhere at a later stage.

The figure shows how new ideas for systems can be devised according to the combination of infrastructural measures and ADAS measures. For instance: vision enhancement systems having the same functionality as already existing reflecting road markings in the infrastructure (for alternative A: road curvature informing at adverse weather conditions). Alternatively, we can also see how vision enhancement systems could help in tunnels, or protecting shoulders.

\subsection{Selection of 18 alternatives}

For the six errors, it was decided to commence with three alternatives to account for every error: in-vehicle, infrastructural, and co-operative vehicle-infrastructural alternatives [12].

Countermeasures for each error were described and each measure was evaluated on effectiveness. Also, for each 
Table 6 The alternative solutions for error 3. Wrong use of lane (error 3). Resulting in: Accidents due to lane departure

\begin{tabular}{|c|c|c|c|c|}
\hline Problem & Alternative & Scenario & Technology & $\begin{array}{l}\text { Communication } \\
\text { type }\end{array}$ \\
\hline $\begin{array}{l}\text { The LDWSystem is deactivated } \\
\text { at the beginning of long } \\
\text { construction sites to avoid } \\
\text { false alarms. }\end{array}$ & \multirow[t]{2}{*}{$\begin{array}{l}\text { F. communication with } \\
\text { the local infrastructure }\end{array}$} & \multirow[t]{2}{*}{$\begin{array}{l}\text { Rural, Highway, all drivers } \\
\text { all vehicles all traffic } \\
\text { conditions, near } \\
\text { construction sites }\end{array}$} & \multirow{2}{*}{$\begin{array}{l}\text { Digital maps/GPS-speed, } \\
\text { ldentity and indicator use } \\
\text { system, Car-to-car } \\
\text { communication via } \\
\text { physicaland link-layer based } \\
\text { on an UMTS terrestrial radio } \\
\text { access network or local area } \\
\text { network }\end{array}$} & Infra $\rightarrow$ Vehicle \\
\hline $\begin{array}{l}\text { When leaving Road } \\
\text { Constructions the driver is } \\
\text { reminded to reactivate his } \\
\text { LDW-System }\end{array}$ & & & & $\begin{array}{l}\text { Infra } \rightarrow \text { Vehicle } \\
\quad \rightarrow \text { Vehicle }\end{array}$ \\
\hline In-vehicle warning of oncoming & G. communication with & Rural, Highway, all drivers & Digital maps/GPS—speed, & Infra $\rightarrow$ Vehicle \\
\hline vehicles In curves. & the local infrastructure & $\begin{array}{l}\text { all vehicles all traffic } \\
\text { conditions }\end{array}$ & $\begin{array}{l}\text { ldentity and indicator use } \\
\text { system, Car-to-car } \\
\text { communication via physical } \\
\text { and link-layer based on an } \\
\text { UMTS terrestrial radio access } \\
\text { network or local area network }\end{array}$ & $\begin{array}{l}\text { Infra } \rightarrow \text { Vehicle } \\
\quad \rightarrow \text { Vehicle }\end{array}$ \\
\hline $\begin{array}{l}\text { Intelligent edge lines (triggered } \\
\text { by vehicle turn indicator) } \\
\text { showing a the right way to a } \\
\text { vehicle exiting the motorway } \\
\text { in case of impaired visibility. }\end{array}$ & $\begin{array}{l}\text { H. Light sensitive sensors } \\
\text { (solar cells based) will } \\
\text { help the driver to see } \\
\text { the edge and centre } \\
\text { lines }\end{array}$ & $\begin{array}{l}\text { Rural, all drivers all vehicles } \\
\text { all traffic conditions-- } \\
\text { running light inserted in } \\
\text { road surface- all weather } \\
\text { esp. reduced visibility }\end{array}$ & $\begin{array}{l}\text { Light sensitive sensors (solar } \\
\text { cells based) }\end{array}$ & Vehicle $\rightarrow$ Infra \\
\hline $\begin{array}{l}\text { In case of inattention the driver } \\
\text { is drifting off the lane }\end{array}$ & $\begin{array}{l}\text { I. } C^{-} D^{a} \text { camera, LDW } \\
\text { system to detect unintended } \\
\text { lane departure and warn } \\
\text { the driver }\end{array}$ & $\begin{array}{l}\text { Rural, Highway, all drivers } \\
\text { all vehicles all traffic } \\
\text { conditions roads without } \\
\text { rumble lines }\end{array}$ & $\begin{array}{l}\text { CCD camera, LDW system: } \\
\text { virtual rumble strips }\end{array}$ & Infra $\rightarrow$ Vehicle \\
\hline $\begin{array}{l}\text { Road works, tunnels, narrowing } \\
\text { road }\end{array}$ & $\begin{array}{l}\text { J. Adaptive LDWA; } \\
\text { Sensitivity of Lane } \\
\text { Departure warning } \\
\text { Assistant is adapted in } \\
\text { special conditions, }\end{array}$ & $\begin{array}{l}\text { Rural, Highway, all drivers, } \\
\text { all vehicles, special traffic } \\
\text { conditions and roads } \\
\text { without hard shoulder }\end{array}$ & $\begin{array}{l}\text { Communication with the local } \\
\text { infrastructure, LDW }\end{array}$ & Infra $\rightarrow$ Vehicle \\
\hline
\end{tabular}

${ }^{a} \mathrm{CCD}$ : A charge-coupled device (CCD) is an analog shift register that enables the transportation of analog signals controlled by a clock signal. The camera contains a chip device and no film.

measure the focus in terms of driver's experience (skill), age, owner and type of vehicle, and the (road) environment (traffic density, road category, special sections, lighting condition, and weather) were defined. In total there were 35 subcategories.

Error 1: Driving too fast in an unexpected bend on rural roads

1. In-vehicle measure: (Unexpected) sharp bends are registered in a digital map of the navigation-system and presented to the driver.

2. Infrastructural measure: The vehicle is "analysed" and a Variable Message Sign (VMS) signalises danger, depending on the measured speed

3. Co-operative system measure: Electronic beacons give additional information on displays in the car about the road, e.g. warning 'too fast', because of local circumstances (weather, etc.), and not only on electronic displays above the road. (this also enable adjusting the language of the information according to requirements of the driver). All three measures have a focus on rural roads
Error 2: Speeding

1. In-vehicle measure: a speed alert system in the vehicle by camera based posted speed sign recognition

2. Infrastructural measure: Speed limit is set under consideration of special environmental circumstances and is presented to the driver on a VMS

3. Co-operative system measure: Speed alert based on digital maps that contain legal speed limits, environmental input by electronic beacons

Error 3: Wrong use of road

1. In-vehicle measure: a camera based Lane Departure Warning System (LDWS)

2. Infrastructural measure: audible lane delineation ("rumble line")

3. Co-operative system measure: Adaptive LDWS: the sensitivity of Lane Departure Warning System is adapted in special conditions, such as road works, or in tunnels

Error 4: Violation of priority rules

1. In-vehicle measure: posted traffic sign recognition (camera based) 
2. Infrastructural measure: traffic signs (stop sign, approach priority road sign)

3. Co-operative system measure: traffic light status emitted to the car

The focus of the co-operative system is on dense traffic (e.g. large lorry in front obstructing view on traffic light) and on adverse weather conditions.

Error 5: Overtaking failure

1. In-vehicle measure: blind spot detector indicating that one is being overtaken

2. Infrastructural measure: separation of lanes by rumble strips where overtaking is not allowed

3. Co-operative system measure: a co-operative system warning for oncoming vehicles by vehicle-tovehicle communication

Error 6: Insufficient safety distance

1. In-vehicle measure: a frontal warning system (e.g. radar based)

2. Infrastructural measure: VMS fog warning

3. Co-operative system measure: adaptive frontal warning systems: the sensitivity of the system is dynamically adapted on the basis of local (e.g. weather) circumstances.

\subsection{Estimation of potential of safety effects}

One of the major criteria defining the safety benefit of a measure was the contribution that each scenario makes to the goal of avoiding or mitigating negative consequences of driving errors. By analysing the accidents, it could be estimated how many of these historical accidents have been caused by errors that could theoretically be addressed by the discussed scenario [13]. But usually not all of the accidents that theoretically can be addressed by a new scenario will be really avoided after implementation. Therefore an assumption on the proportion "avoidable accident" must be done as well.

In order to make these assumptions the possible conditions of a later implementation must be described. The answers to the following question will set the "boundaries" of a scenario:

- If the measure needs equipment in vehicles how many of the vehicles might be equipped with the system?

- If the measure is informative (not "overruling") how many drivers might follow the recommendations?

- If the measure is not addressing ALL drivers equally which type of drivers should be addressed?

- etc.

To answer these kind of questions more specific information was required on driver, vehicle, traffic and environmental conditions. There are a number of (decisive) criteria that have a strong influence and need to be specified. Some are typically important for the drivers, others are more important for the society as a whole (public authorities), and others are important for manufacturers. Amongst these criteria are comfort, investment and user costs, technical readiness, et cetera (eSafety Forum).

\subsection{Multiple criteria analysis}

The MCA methodology as an evaluation approach has a long tradition and has its roots in operational research (OR) [2]. More recently, it has been applied in the context of economics-driven project evaluation.

MCA allows comparing a number of actions (for instance, projects or policy measures), or alternatives in terms of specific criteria. These criteria represent the operationalization of the objectives and sub-objectives of decision makers and stakeholders participating in the decision-making process. The MCA methodology is especially useful to structure complex decision problems according to their constituent parts (objectives, subobjectives as measured by criteria), to make comparisons among project alternatives. This approach appears especially useful when effects cannot be fully monetised, nor even quantified. It is usually possible to link specific stakeholders with specific criteria in the MCA, and by doing so stakeholder management can effectively be implemented, as described in Macharis et al [6].

Central in the MCA procedure is the assessment of the relative weights of a set of criteria contributing to forgiving road and self-explaining road environments. For this purpose, a twostep procedure was followed. First, a special workshop ${ }^{1}$ with leading experts coming from INSAFETY consortium partners was organised. At the end of this workshop, the experts agreed on a decision tree as presented in Fig. 4.

The top level of the decision tree shown in Fig. 4 represents the focus or overall objective, namely creating benefits by making the road environment more forgiving and more self-explaining. At the second level, three groups of main stakeholders are shown, namely (1) the users, (2) society/ public policy makers and (3) manufacturers. Within each group of stakeholders, a number of subcategories could be identified such as drivers, fleet owners and emergency centres (for the main category 'users'), road managers and

\footnotetext{
${ }^{1}$ This workshop took place at the Technical University of Delft (TUDelft), on 6 and 7 February 2006 and welcomed experts from the Bundesanstallt für Strassenwezen (BAST), this is the German Federal Highway Research Institute, the Technical University of Darmstatt (TUDarm), the University of Stuttgart (USTUTT) and the TUDelft itself.
} 


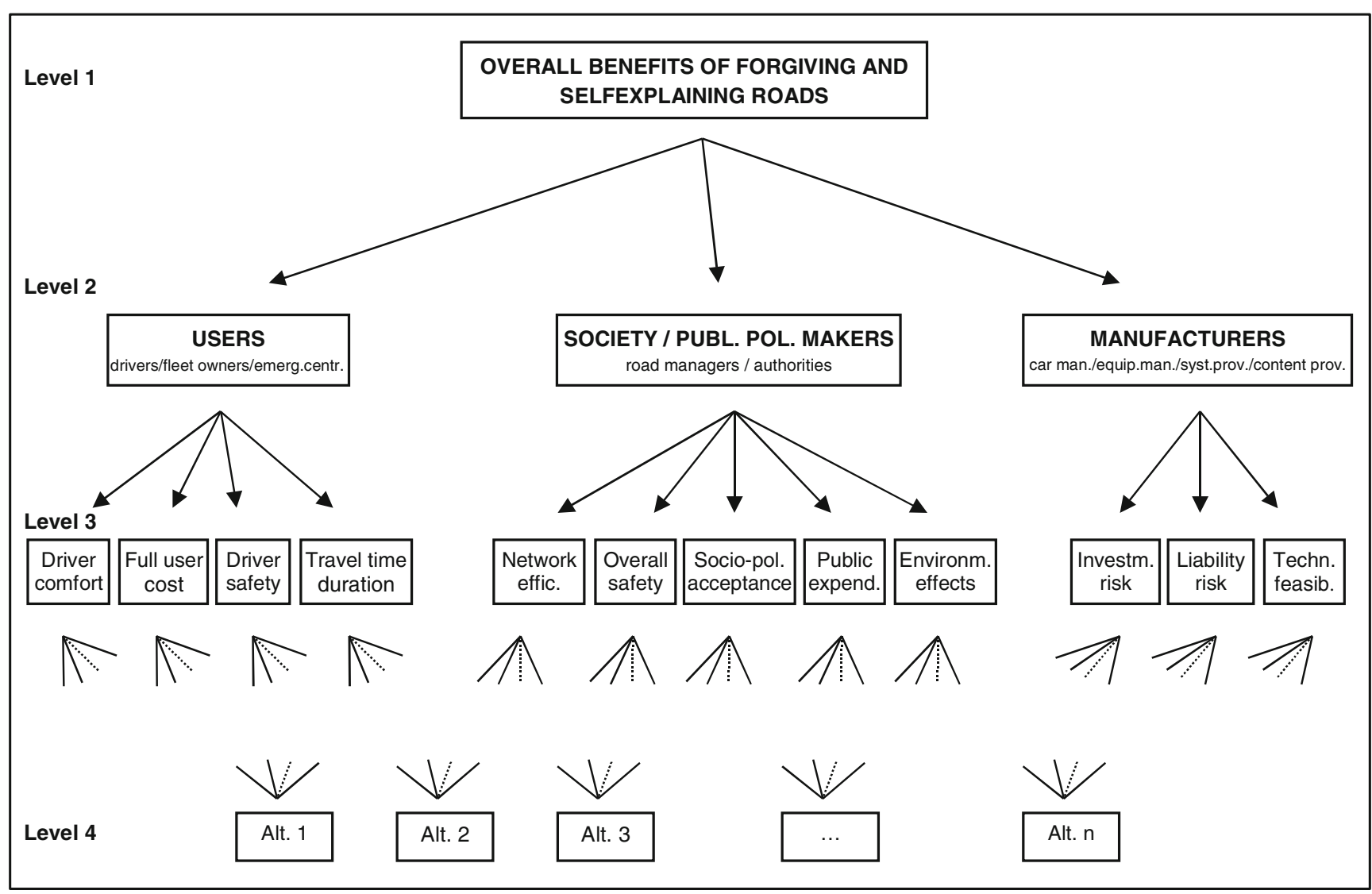

Source : IN-SAFETY project team

Fig. 4 Decision hierarchy for the prioritisation of FOR and SER alternatives

authorities (for the main category 'authorities') and car manufacturers, equipment manufacturers, system providers and content providers (for the main category 'manufacturers'). As regards these subcategories, it turned out that it was not necessary to include them as separate groups, since the preferences of these subgroups were not substantially different from each other and since some of these subgroups were not organised in such a way so as to exert a substantial influence on policy making. At the third level, the criteria are listed that these main stakeholders consider relevant. At the lowest level, the alternatives are shown that need to be prioritised. Please refer to De Brucker et al (2007) for detailed results.

\subsection{Prioritisation of scenarios}

The results showed that, for the public authorities, preferred safety measures are characterised by minimal infrastructural investments, and "speeding measures" considered the most important. For users, "too fast in unexpected bends", for manufacturers: violation of priority rules. Manufacturers preferred safety measures with minimal investment for the vehicles.

\section{Discussion and conclusions}

The methodology which was adopted showed the following strengths and weaknesses. To start from the accident analysis data, in this case from the German accident data, there is a sound basis for selection of FOR and SER environments. However, investigating safety measures, we could see that there is an emphasis on measures that can be applied in rural and motorway environment, rather than urban environments. The safety hazards and the measures for vulnerable road users were under represented. For this reason, it was decided in the In-Safety project to select also measures for vulnerable road users, in particular school children. Furthermore, the list of possible safety measures is not exhaustive. In the InSafety project, focus was mainly on measures that are not too far away from the market. More innovative measures could be imagined, and should be developed. The safety assessment of measures that did not exist, on the basis of resemblance to infrastructural measures is a viable option. At a later stage in the project, also data from modelling activities and pilot site evaluations can be used for assessment of safety effects. 
The Multiple Criteria Analysis shows that the different stakeholders will prefer different types of safety measures. Public authorities should be aware of this, and develop policy actions to cover for the problems the industry and the road users will experience in case of a safety measure which does pose serious disadvantages for them.

Open Access This article is distributed under the terms of the Creative Commons Attribution License which permits any use, distribution and reproduction in any medium, provided the original author(s) and source are credited.

\section{References}

1. Brookhuis KA, De Waard D, Marchau VAWJ, Wiethoff M, Walta L, Bekiaris E (2006) Self-explaining and forgiving roads to improve traffic safety. In: De Waard D, Brookhuis KA, Tofetti A (eds) Developments in human factors in transportation, design, and evaluation. Shaker Publishing, Maastricht, pp 51-63

2. Charness A, Cooper WW (1961) Management models and industrial applications of linear programming. Wiley, New York

3. De Brucker K, Verbeke A, Macharis C (2004) The applicability of multicriteria-analysis to the evaluation of intelligent transport systems (ITS). In: Nakanishi YI, Bekiaris E (eds) Economic impacts of intelligent transportation systems. Innovations and case studies. Elsevier, Amsterdam, pp 151-179

4. Lotz C (ed) (2006) A1.1 Benchmarking of Forgiving Road Environments. In-safety report IN-Safety-BASt-WP1-R3-V5Activity11. Bergisch-Gladbach, Germany: Bast.
5. Lotz C, Brookhuis K, Bauer A, Wiethoff M, Marchau VAWJ, de Waard D (2006) IN-SAFETY - Towards 'Forgiving road environments': implementation scenarios for road design measures and ITS solutions. TRA, Europe 2006 Conference.

6. Macharis C, Verbeke A, De Brucker K (2004) The strategic evaluation of new technologies through multi-criteria analysis: the advisors case. In: Bekiaris E, Nakanishi YI (eds) Economic impacts of intelligent transportation systems. Innovations and case studies. Elsevier, Amsterdam, pp 439-460

7. Rasmussen J (1982) Human errors. A taxonomy for describing human malfunction in industrial installations. Journal of Occupational Accidents 4:311-333

8. Saaty TL (1980) The analytic hierarchy process: planning, priority setting, resource allocation. McGraw-Hill, New York

9. SAFETYNET (2004) Building the European Road Safety Observatory. Workpackage 1-Task 3, Deliverable No 1: Annual Statistical Report 2004 based on data from the CARE database.

10. Vollrath M (2005) Fehleranalysen bei Unfällen und Anforderungen an die Fahrerassistenz (Analyses of errors on accidents and requirements on driver assistance systems). Presentation at the "Deutscher Verkehrsexpertentag 2005".

11. Wiethoff M (2003) Final Technical Report ADVISORS. GRD1 2000-10047. The European Community under the 'Competitive and Sustainable Growth' Programme. Uitgave: SWOV, Den Haag, 2003, pp 108.

12. Wiethoff M, Marchau VAWJ, de Waard D, Walta L, Brookhuis KA, Maccharis C, de Brucker K, Lotz C, Wenzel G, Ferrari E, Lu M, Damiani S (2006) Implementation scenarios and concepts towards forgiving roads In-Safety Deliverable D1.1. In-Safety project 506716.

13. Wiethoff M, de Waard D, Wenzel G, de Brucker K, Spruijtenburg E, Brookhuis KA, Marchau VAWJ (2008) Expected Safety Effects for Driver Assistance Systems. AATT Conference, May 2008, Athens. 